\title{
CIRURGIA ORTOGNÁTICA PARA CORREÇÃO DE RETROGNATISMO MANDIBULAR-RELATO DE CASO
}

Isabelle Ribas de Lima SILVA, Fabiano GALINA, Leandro Eduardo KLUPPEL, Rafaela Scariot DE MORAIS, Nelson Luis Barbosa REBELLATO

O presente trabalho discorre sobre 0 restabelecimento da harmonia facial em um caso de retrognatismo mandibular. Paciente R.A.F,classe II esquelética, gênero feminino, 19 anos. Procurou o Serviço de Cirurgia e Traumatologia Buco-Maxilo-Faciais da Universidade Federal do Paraná com queixa estética. $O$ exame clínico indicou um perfil facial convexo, retrognatismo mandibular, sulco mento labial pronunciado, pouca protusão mandibular, mas com boa abertura bucal. Havia dor na região do masseter e estalido em ATM esquerda. Observou-se uma relação ântero-posterior maxilar harmônica com a base do crânio. O plano de tratamento proposto foi um avanço linear mandibular, através da osteotomia bilateral sagital. A mandíbula reposicionada foi fixada com 6 parafusos bicorticais. O resultado obtido foi compatível com o planejamento pré-cirúrgico. Após o procedimento, o acompanhamento do caso revelou boas condições estéticas e funcionais.

Palavras-chave:Ortognática; Retrognatismo; Mandibular 